\title{
关于我國植物生理学 12 年远暴 規划的一些建議和資料
}

湯誠松

（中國科学院生物学地学部委員）

从总的方面說, 植物生理学的規划是为了滿足兩个要求: 从本門科学看, 要求能在 短期內接近國际先進水本。从國家絰济毽設的任务看, 要求密切配合農業生產規划。需 要解釋的是: 接近先進水平的标准和配合農業生產的意义。对接近國际科学先進水平的 最低要求, 我認为应做到在本門科学內的任何部分, 有必要时我們能泣即重复世界上任 何学者的最近工作, 半能对他的工作的意义加以陴論, 虽然在看法上可以不闰。对密切 配合農業 (或工業) 生産規划, 我認为应当要求能从農業生產規划（如五年訃划）中預 見到对本門科学的要求, 从而及早着手研究一套方法或原理, 能指導生產的技術, 至少 应能滿足生產技眞進度的要求而不落后。例如: 虽然化学肥料目前份未大量使用, 植物 对氮磷銅需要的比例应当早日做出, 以为建厂的参考。而这个呼究的先决间題是植物生 理学者的工作: 制訂一套标准生理指标去衡量植物在各时期对元素的需要, 这都是需要 时閣的工作，因此要能預兄。

如果以上所体会的关于國际水平及配合生逵的解釋是可行的話, 那末这涵个要求也 包含对植物生理学發展的另外三个要求: 在数量上, 机構与幹部必須能㴖边这涵个目标3 在工作的質是上也必須达到这个目标所要求的水平；同时当然也必須先后汾娍一切空白 点。在从事質同量的梘划中我認为首先应从生燮計划的要求州發, 而科学的完整性則是 必然的結果。很有可能由于实踐的要求而我們又能㓱立新的科学領域。我这个看法决不 等于將科学看成單純为技術服务而被应用所限制, 但是我不希望脱离实际情况單紨 “追 求國际水本”, 为补空白点而补空白点。

以下就从植物生理学各部門的目标和方向、國际情况、國內情况、國內情况与國际 情况間美別的关践等分別來剠我國植物生理学 12 年远景規划。

\section{一 光合作用}

1. 目标及方向: 以光合作用的机構为主, 从而达到人工光合。不但是植物生理学的 基本問題, 是生物学, 是自然科学的一个重大的理論和实际的閵題, 应作長期重点研 究, 集中一定的有力幹部, 包括植生、生化、有机化学及物理学幹部, 开始工作。

2. 國际情况: 1937 年前后 Hill 反应, Wood \& Werkman 反应及 Van Niel 的理 酳, 开始光合作用新階段。 
1949 前后, Ochoa 及 Vennesland 等的 $\mathrm{CO}_{2}$ - 同化反应。

1953 前后, Calvin 等对中間迹物为磷酸甘油酸的肯定, 及其他䤃类的發現。同时, 各种酶的分离及作用的進展。到目前止：Calvin 等在 1955 年日內瓦原子能和平利用会

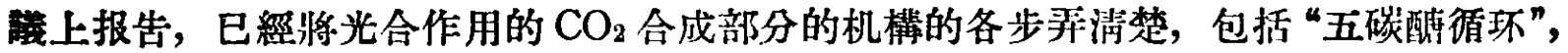
“三羒酸循环”, 及磷酸脂化(Phosphorylation) 无其三磷酸腺式(ATP)的轉能作用。Arnon 及 Vishniac 的离体叶綠素光合作用 (1955), Hill 和 Vernon \& Kamen 对末端氯化酶在 光合中的作用 (1955), Warburg 等对光合作用量子效率间題的解决 (1954)。这些工作 指出：目前关于光合作用这一重大問題已經从“摸索階段”淮到能具体的用生理、生化和 物理的途徑及方法, 利用由酔时及肌肉生物化学研究成果的知識進行深入研究。总結 目前关于光合作用的研究, 我認为今后的方向同工作是将光合作用分作以下几方面去淮 攻的。当然在淮攻中放射性同位素是重要工具之一。

（1）能的利用。今后不只是光能, 而是任何的能, 包括电磁能、氧化还原电位能 等, 只要它們能將能傳遞到三磷酸腺代上去。在目前看來叶綠素的功能主要是在将光能 博为三磷酸腺式可用能。

（2）化能合成的中間迹物，或 $\mathrm{CO}_{2}$ - 同化的中間步䮴, 这項包括类似呼吸作用中 的: 酮解 (Glycolysis)、有机酸代謝及三羒酸循环, 以及五碳糖的轉变等等。

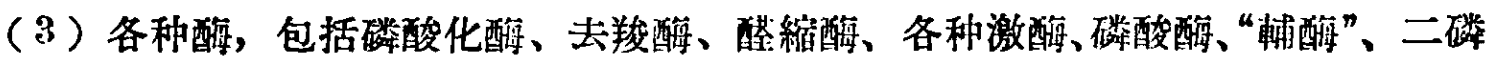
酸吡啶 (DPN)、三磷酸吡啶 (TPN) 等的活动研究。

(4) “末端攻化酶”及去氧酶的政究。研究 $\mathrm{H}_{2} \mathrm{O}$ 的氯化 (分解) 同 $\mathrm{CO}_{2}$ 和 $\mathrm{O}_{2}$ 的 还原的步㵵。

过去 10 年的發展已經將光合作用过程的認識达到同目前对肌肉与狆酵的代謝 过程 镬識的程度一样。而肌肉与發酔代謝的生化, 自 Büchner 的工作起, 是花费了 40 年的 工夫（1900-1940）方完成的。因此很有可能在 12 年后, 可以進行試管規模的“人工光 合”的原理性的研究。

3. 國內情况: 我國在光合作用中的工作，不只是量少，而且做的工作亦早已过时，

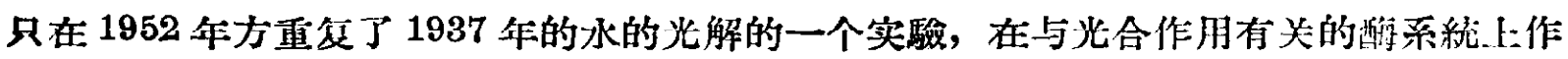
过磷酸化酶及碳酸酩酶, 只此而已。目前正在進行光合作用工作的有植物生理破究所生 化組和北京大学植物生理称研室, 但工作份在开始階段, 非常虚淺。而在近十年承酎外的 光合作用論交則数以千計。

情况是这样，但这个工作是一定要作的。玩在有利的条件是: 光合作用的兴趾開題 及方向在这兩年方明确, 甚至晌末明确的提出。如果上段所提出的方向是正确的話, 我 佃可以在近代研究成就的基礎上迎头赶上去，还是可以節省許多时間同力目的。

今后我們的方泃应是在目前的基礎上結合農業和工業的需要在具体的个別植物的光 合与代謝上進行上面四类的研究: 例如稻麥棉和大豆的光合作用, 醉母菌的代謝和有机 酸的發酵（見下面代謝部分）。一面为生產技衔打下理論基礎，一面全面学㕷光合作用研 究的方法与進一步提高理論。在 12 年內的主要目的是爭取在第三个五年郡划完成以前能 將中國关于光合作用的研究提高到这么一个地步：当人工光合作用只有試管或学術性的 可能时, 我們可以立即進行工作。 
4. 关鍵問題: 从学科發展看來, 光合作用之所以在近十余年本有这样快的進展, 除 一般的条件外，关鍵在：近代生物化学对中間代謝过程的成就；在技迶上，由于放射性 同位素的应用，和紙諸分析及相类的分析方法的發展。从國內具体情况承珫，除了上迅 三个关䣄外, 一个重要关旔在对这个問題的重覙不够, 認識不能。因此沒有一个人将他 的全力放在此項工作上，作为一个重要任务去㓱造条件克服困难。而这个工作不但要求 少数人將全副精力集中在此, 玤且要求一个相当大的榢伍分头在上述四項方向中鑽研。

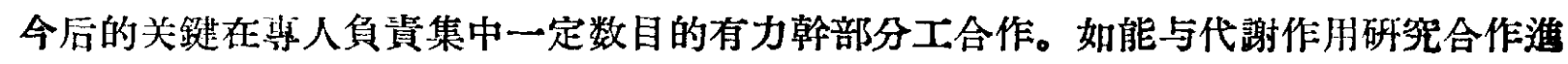
行, 互相补助, 是最合理的。因为这样更可以收“事牛功倍”之效。

\section{二 高等植物有机物䨢代謝}

1. 目标及方向：研究高等植物中有机物質（主要是碳水化合物、蛋白筫、脂乃j)的同 化 (光合除外)、异化的途徑及它們在体內的运輸, 新陈代謝类型及其变异, 物質轉化与 形态建成。此項为植物生理学基礎之一，鿑其在米差林生物学中指出代謝作用在植物与 环境統一中的主动作用。在实踐上需要了解代謝及其变化的規律从而更好的控制植物的 生活活动。此项与光合作用有不可分割的联系, 应与光合作用的砾究結合隻行。

2. 國际情况：由于过去对植物代謝了解不够，因此此項工作沒有一个全面的方问. 过去只孤立的研究了呼吸、运輸同消化, 因而缺乏完整認識。就在这三方面, 也只有对 呼吸作用方面的工作比較多。到目前为止对运輸及酶中間代謝的工作甚少开展。近年本 由于苏联对新陈代謝类型的研究, 开展了这方面的新的理論路綫, 另一方面由于动物生 化的成就，帶动了植物中問代謝工作。这些發展主要在 1945 年前后3 目前此項工作在下 列各方面進行着:

(1) 新陈代謝类型及酶活动性研究: 主要是苏联 Опарин 同他的学派,包括 Сисакян、 Рубин 等人的工作。

（2）植物体內碳水化合物的中間代謝: James 1944 开始, 至 1950 左右英美方面对

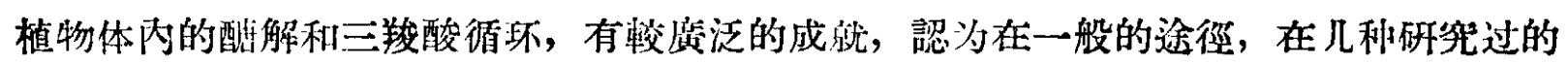

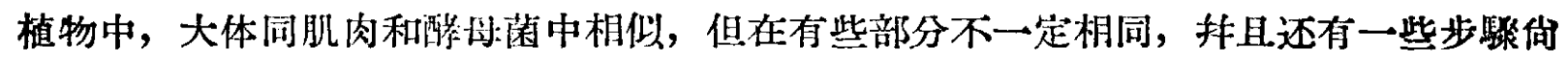
不肯定。在有机酸的合成与分解上也开始了工作䄶开始与光合作用結合。

(3) 植物代謝的酶系統: 只在末端氧化酶上有过工作，但不系統。磷酸化酶及其 他的醮解酶研究虽已开始, 但不的完全。植物的去氢酶只是近兩年方有較深入的研究。

(4) 植物的脂肪代謝向未开展, 氮同化的研究何無新的發展。由于植物油在中國的 特殊世界地位, 植物脂肪代謝应是今后中國植物生理学重点發展的。

（5）有机物質在植物体內运輸的途徑这一个極重要的項目至今向無系統的知識，近 年來由于放射性同位素的利用方有开端, 但还远远不能。这不論在理論上和实踐上都是 極应开展的工作。在实踐上如果全面了解了物睤运输的規律, 農作物及果樹的聕品的量 同犋方面，在花果的脱落或保你方面，应能指出控制的途徑。

(6) 一个植物生理学上的重要問題: 物質如何轉变为器官及其規律, 在全部植物生 理学上說來少是空白点。它在理論及实踐上的意义是很顯明的。

3. 國內情况: 过去虽在个別部分如呼吸、細胞色素氧化酶及其他問題上有一些工 
作, 但無系統研究。如能在过去基磷上楼續淮行, 向不难在三五年內接近先淮水本, 只是 人手間戛同工作条件。建議立即指定專人負責進行下列基本工作, 玤最好与光合作用研 究的部分集中在一个地方工作。这样在人力、設备及経驗交流方面会起很大的作用。

工作項目：（1）新陈代謝类型及其改变: 在農作物方面研究小麥或水葐（为例）各

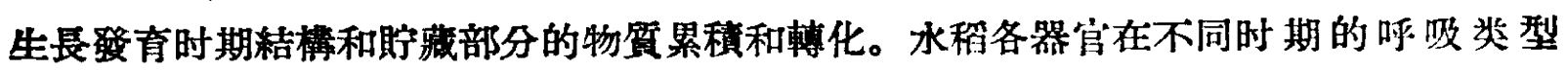
等。在微生物方面方心芳等关于醳母菌对高温適应前后新陈代謝类型的改变是理論与实 际結合的例子。高等植物中也应争取这样作。

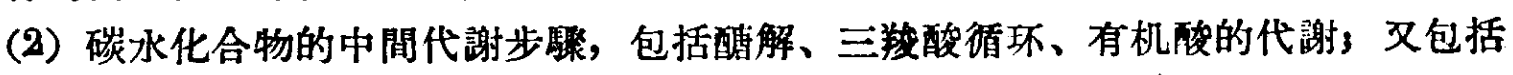
有机酸与 $\mathrm{CO}_{2}$ 的合成 (羧化) 及有机酸的胺化 (Amination), 尤其是內酮酸。

(3) 有氧呼吸与無氧呼吸間的关系及改变, 即所謂“巴斯德效应”的研究。对晨作物 如稻子及果蔬的聍藏有重要实踐意义。

（4）末端氧化酶及去氢酶的作用，与这些作用有关的“輔酶”如二磷酸吡啶、三磷酸 吡啶及維生素 $\mathrm{C} 、 \mathrm{~K} 、 \mathrm{~B}$ 等的作用. 它們在各生長时期的活动强度, 和影响它們活动的因 来。

（5）代謝作用中能的轉变。主要在磷酸脂化作用和氧化还原势能的作用。因为这是 生物合成, 光能合成, 和䃥罂元素吸收等作用的基礎。可結合实际間題工作, 如水稻根 的呼吸与䃥買吸收。

（6）由于植物油是我國的特殊或特別重要的在品，在世界上有其必要和优越的条 件, 植物的脂肪代謝应配合后面“植物生物化学”項目下关于植物沁的研究开展。

4. 关趾問題, 主要在人手不足。目前这些工作的一部分已开始, 但中級幹部不够。

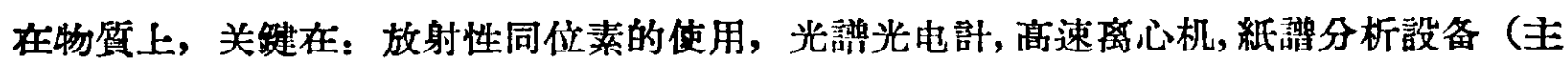
西是紙)，交交換材料的供应。必须將此工作同光合工作放在一起。

\section{三 硣物䆝营苏}

1. 目的与方向: 植物發育及生長各时期对某些碛物元素的買同量上的要求; 砤物元 秦進入植物体的机構; 元素在植物体內的移动及分布; 磺物元素在植物代謝中的作用。 在新發展的問題方面有: 微量元素对植物生長的效应3 根外施肥的生理原理3 根际微生 物活动与植物营养的关系 (細菌施肥及固氮作用等)。

2. 國际情况: 近年來的發展, 一面是将誉質营养問題深入研究, 作为具体的生理过 程, 如: 元素如何進入植物体, 如何运轉及分布, 和元素在代謝中的作用。另一方面, 主要是苏联的工作，从植物的生長發育出發, 研究植物对元素的質同量上的要求, 将植 物作为發展着的整体对待, 这是一个正确的新方向。同样的, 从土壤微生物活恸与植物 根系的相互关系出發而發展根际的研究也是一个正确的方向。虽然微量元素的应用和根 外施肥不应作为磺物营养的單独方向, 而是農業技街措施, 但因其突出的發展, 这些措 施的理論和原理是可作为特殊問題來研究的。

在元素淮入植物根部的生理机粠問題上, 从 1949 年后由于 Lundegardh 学派的工作, 巳开始了一个新的階段。从 1950 年左右开始, 元素的代謝作用由于 Hoagland 学派 (Arnon 等) 的工作也深入到酶的作用。在元素的移动及分布問題上, 由于 Biddulph 等应用了放 
射性同位素在 1941 年后也开始了進一步的發展。

3. 國內情况：在过去有着一定的基礎。罗宗洛及植物生理研究所䃫啠营筷組的工作 已進行分期施肥的生理研究, 在罗宗洛过去成就的基脴上也正着手研究微量元素的应用 及生理研究。偵得提出的是 1950 年左右彭謙在苏北弯場曾進行研究棉花的根外施磷, 科 有一定結果。当时因是解放不久, 尚末得到苏联关于这方面的資料，他的工作在当时倘 是創举, 每受到一些責难, 但他仍坚持研究。林傳光解放前在四川时僧作水稻的敛及氮 的营新研究, 这是个好开始希望能繼縝下去。四川農研所鵤交奎等关于水稻的施肥工 作，虽然是从農業实踐出發，应栈纊从生理方面深入研究。

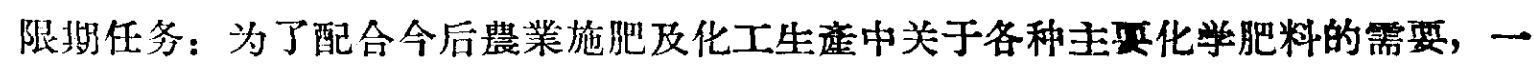
个特殊而限期的任务是: 在三年內制訂出主要農作物对氮磷鉀肥需要且的生理测定方法。 这个工作植物生理研究所应在三年內訂出，然后艾給各大区教業研究所淮行研究， 在第三个五年計划开始时应能提出全國鋠業生在中化学肥料的需夏量。

4. 关旔䦌題：由于罗宗洛及他的学生們的工作，磺物营养䂰究在國內是有一定基㯬 的。关舒問題在明确方向。在方法上，关鍵在放射性同位素的技術。在特殊任务上，三 年內訂出测定稻麥棉及其他主要作物的需肥量的生理測定方法。

5. 植物生理研究所有罗宗洛、湯玉瑋、金成忠; 南开大学槯烄; 北京大学曹宗巽合

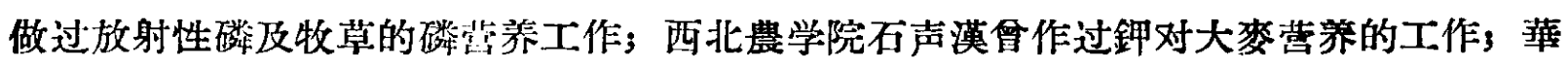
中農叶科学研究所彭謙在根外施肥做过工作; 林傅光管在水稆营养上工作过。科学院土 坮䂰究肪的一部分工作的性質是屬于此的, 各農業研究所的肥料研究工作, 大多与此有 关。如能全面烧划組織，应当是一支强大的榢伍。

\section{四水分生理}

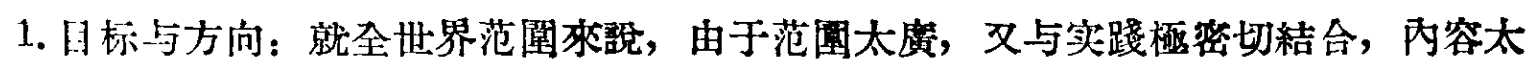
多，因此重点不明，工作不椮深入。这項工作的目标和方向結合下面的国际情况影。

2. 四际情况: 据我个人的看法, 水分生理的發展情况可以分为下列 6 个內容叙述,

（1）水的淮入細胞。虽然过去有 Ursprung 的吸水压概念, 目前仍稓滿意的看法。 1930 后由于 Bennet-Clark 等的“非滲透性”吸收的学諮提出, 将水分吸收联系到細胞的 代謝作用，因此这个間題的看法正在轉变中。轉变的趋势是泃代謝方面。

（2）水分掉失及其动力, 蒸腾流。Dixon 的水分內皘力学詵由于近年來㚭其是 1955 年的研究, 已开始被动搖。但目前向無更好学詮。

(3) 植物根系与土壤保水力的关系和萎噳。自 1919 年 Briggs \& Schantz 后基本上 無新的進展(純土壤物理学的工作除外)。

下面三个內容主要是苏联的成就，同时既是重要問题，又是發展的方向：

（4）植物体內水分調節及分布一一包括各器官間，上下部位，在不同發育时間及外 界因素影响下的相互調節。馬克西莫夫关于植物对失水的非气孔調節学說是由这个覌点 出發的。此項工作应發展。

(5) 植物在各生唇發奇期間的需水量的工作，苏联目前大量开展。

（6）抗早及灌餉生理基礎，包括抗旱性的測定方法，需水期的生理測定方法，合理 
灌溉同由水分不調（过多或过少）而引起的代謝变化。苏联在此項有大的進展。通过按 植物的需水期而灌溉不但節省了水, 玤提高了量。

3. 國內情况: 虽然水分生理是植物生理学的一項重要项目，但过去國队这方面的学 很性論交極少。目前已开始着手研究。我建議目前五年內将重点放在下列四方面:

（1）限期任务：配合國家水利建設及灌溉計划, 植物生理研究所在三年內訂出主要 作物需水期及需水量測定的生理指标。訂出后交給水利及農業部阴作实地研究。

（2）䊅合具体岪業上的問題, 如棉花的落花落鈴, 研究水分在体內分布及在各器官 間的调節。

（3）結合表業规划与兴修水利的措施進行灌溉生理的研究。

(4) 粘合水利建設的需要進行主要作物抗旱抗澇的程度及提滈抗性的方法。

4. 关踺問題: 此項工作無設备上的困难，关踺只在对水分生理研究的总目标、方向 和重点的明确。与水利、農業及其他有关部門的联系。

5. 國內進行此項矿究的机構及人員較多, 目前植物生理研究所由罗宗洛領萁的水分 生理組在進行抗早性研究; 南开大学槯改研究水稳灌溉生理; 西北㤟業生物研究所石声 漢开始了水分生理研究; 水利部也進行了灌溉及需水量的研究。建議今后此項工作以南 开大学为中心, 联合水利和農業研究部門, 西北蕽業生物所, 植物生理所水分組, 共同 統一規划，集中力量分工合作。無論如何关于主要農作物需水时期及量的生理測定方法 必需立即开始，限三年完成。

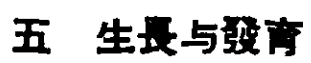

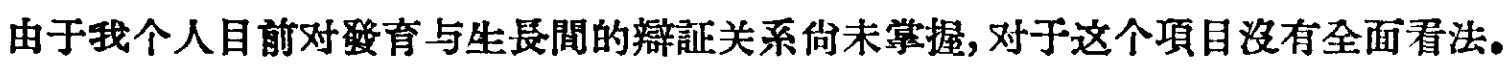
因此只將个人看到的一些問題和想到的一些意見提出作为参考。

1. 关于生長方面提出下面三方面的問題:

生長素, 类似生長素等物質在農業生產上的应用和这些物質的生理作用原理. 包括 插条生根、促淮生長、殺草、疎花、打頂、防止脫落等。这是近年本植物生理学破觉对

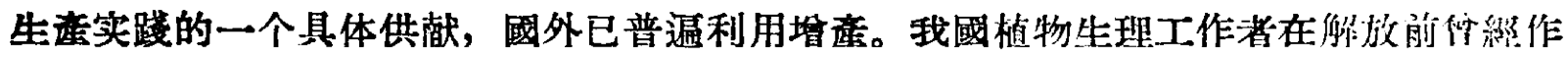
了缽多工作，有一定成精，而解放后近乎停頓。这項工作应立即努力开展。

主要農作物生長过程中体質結構的化学性質的变化的研究。我們对点些植物的体冥

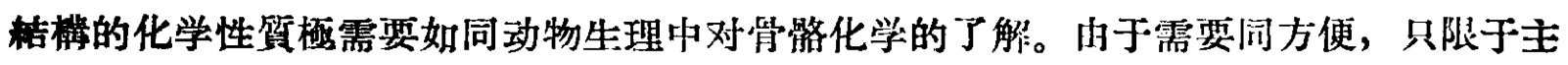
要農作物。这些資料不但对理論上会有供献, 种且是今后農業生産上必需了解的对像; 如同：倒伏的原因及防止，農業副產品的合理利用，令料效能的提高等。

第三个方向是植物各器官間, 各部分間的生長过程的相关性的礃究。目前关于相决 性問題有三方面的發展: (1) 根冠比例及影响它的因素; (2) 苏联植物生理学工:作者 提出的“合理結構”的研究; (3) 英美 (Wardlaw \& Weston) 所發展的試驗形态处成 学。我建議今后中國植物生理学应在这个总方泃, 包括三个具体方向進行研究, 以泳抄的 “合理粘構”的方向为指導思想, 从实际問題如: 徒長、倒伏、收穫量等出發, 用試噞形 态建成学的一些方法, 应当在实际同理論上均有供献的。

2. 关于發有生理, 我想提出下列兩个問題討論: 
（1）階段發育的物貿基礎。过去六年, 中國植物生理学及農菜科学工作者对階段 發育学㽬学㕷很努力，也有不少的好的成績。这类工作应巩固加强。但从植物生理学的

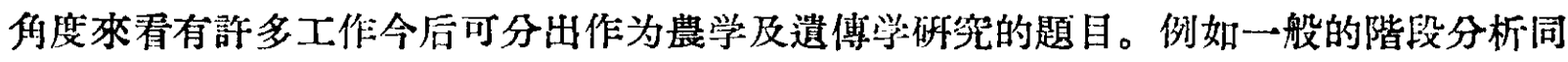
無性新㚆的工作可以交出，而將主力放在哚入啍找外界条作对階段發育如何起作用：从 物理、化学的机棈, 从器官形成的步婜上哚入破究。在这方面李曙軒的工作已有好的开 端; 植生所店䤢華和夏鎮澳关于水稻及小麥的工作也正轉向这个方面。希望今谷能面加 强, 抹与生物化学及物理工作結合, 使其更能全面。

（2）在人为控制条作下研究枮物各时期各階段对外界条件的要求。突出的例子是 Went 近年來开始的人工气候室的工作，对于“光周期”的研究。他的思想体系是錯誤的. 这个方向应当在正确的思想体系下進行研究。目前國內在这方面的一个突出成就是售呈 奎等用米丘林生物学思想指導, 經过这个方向而解决了紫荣的生活史問題。这个工作說

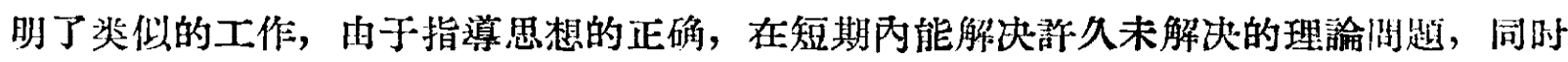

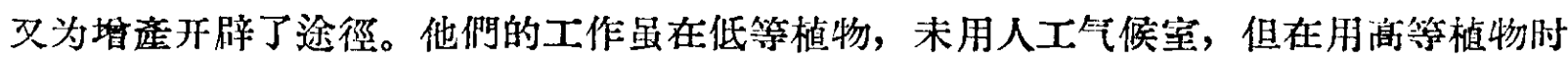
再加上人工控制环境条件，是可以得到同样的成就的。

总起來說, 發育生理的工作今后应从生理学的角度滥行哚入的研究而不必做一般性 工作，在这个原則下，進行与農業及遺傅研究的合作与分工。

\section{六 細胞生理}

1. 目标与方向：細胞生理是植物生理学基礎項目之一，有理論和实踐的重要性。有 下列方问: 細胞原生質結構; 細胞的物理化学特性; 細胞內各組成部分的代謝功能; 原 生質狀态与酶活动性的关系; 細胞生理特性作为生活力及抗性湘定的指标。总之䂧細胞 原生質作为一个代謝基碟來研究，以及細胞活动作为生活力及抗性指标。

2. 國际情况: 細胞及原生質的結構及膠体性筫只在 1945 后由于电子䫖微䥋的应用而 有新的進展 (Frey-Wyssling)。細胞內各部的代謝功能是在 1948 以后, 特別是在 1952 年 起方才發展 (Сисакян, Bonner)。目前对于酶在立綫体、核、原生質等中間的分布有了较 肯定的数据。主要的是苏联奧巴林学派关于原生質狀态与酶活动性的正确的見解, 提出 丁新方向; Гинкөль 关于原生質狀态作为抗性指标的研究，也开辟了一个新方向。

3. 國內情况: 过去关于这方面的工作可以說完全没有。細胞生理学是植物生理学一 个基磪項目, 应为代謝、威应性、遺傳發亩、器官形成及其他生理功能研究的基整。在 实踐上細胞生理的一些特性可以用为生理指标，湘定植物生活力及抗性等。

國內目前在此方面有些突出的工作。坚素营关于細胞核的穿壁运动的观察，知國餜 由这个工作而重新研究他过去在百合花粉中看到的同样現像, 把这个現像結合到花粉形 成过程。他們的工作是对机械唯物的細胞遗傳学有力的打击。我建議今后細胞生理学研 究可以把这个工作作为一个开始点, 琫由植物生理所的水分生理組及植物所細胞室开始 長期的工作。

原生筫膜的棈造、物理化学性質及其透性应为此項工作中的一个重点。不但由于其 本身的重要, 是生物与环境統一的一个关鍵, 讲且这个問題獲得解决, 其他如水分、碳 贸的進入植物体問題, 运輸問題, 以及抗性的問題等也就有了基碳。 


\section{七 植物的感应性}

在植物生理学范圍內这是一項長期沒有淮展的項目。原因在过去未能联系实践, 抹 且沒有中心思想, 因而在理論上亦無發展, 而停留在表面現像的叙述。由于米丘林生物

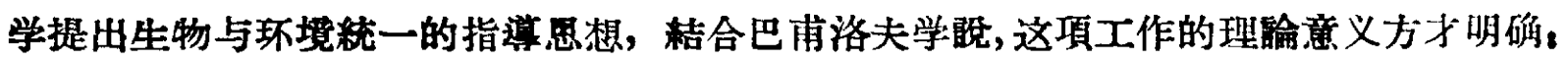
是动植物生活活动間的一个共同表現。

中國植物生理学的一个突出工作是基成后多年來的一系列以电生理学为工具的植物 成应性研究, 其中包括与萨应龍合作的許多工作。由于学㕷了米丘林生物学原理与巴甫 洛夫学說, 从这些工作中樑刻的体会到植物原生質的連繶性意义。这件事实說明了随有 中國人民革命成功, 解放了中國的科学思想. 有了正确的折学指導, 科学的成就就有迅 速的提高和發展。如果将吳素营及鄭國錩关于湅胞核运动研究同婁成后的原生筫逨繶性 研究䊅合本看, 我噼为这是近代細胞生理学中理論性研究的一个好的初步成就。

植物威应性的工作不但已达到目前國际水平, 玤且本身就是先進水平。今公这个工作 不但应在本項目范腦內提商, 为了巩固和發展, 必須結合細胞学的各項工作進行。

当然此項工作还是植物生理学中一門范图較小、目前较为次要的项目。甚至一般不 作为一个独立項目列出．此项工作规划参閲下面生物物理学項目。

\section{八 生殖生理}

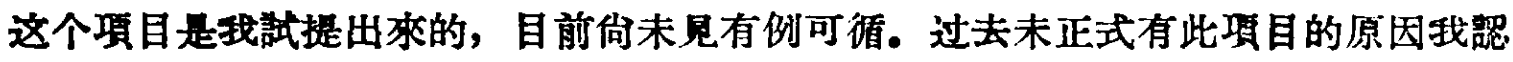
为是由于工作片面。一方面由于实踐方面只求解决实际問題（如休眠、僻藏等）, 而末獎 研究提高到理諭上去, 另一方面由于錯誤的遗傳学說局限了这門理論的發展。从目前看 來一面由于各項工作逐漸互相联系, 另一方面, 更主要的是有了新的生物学䙺点, 这些 片面“零星”的項目可以包括在“生殖生理”中. 这样不但可以系統化, 秚且可以提高理論, 从而又对实踐有所指導。我的不成熟 (不一定正确) 的看法, 此項研究的目的和范阅是: 从受粉开始經过种子成熟、休眠等过程到种子萌發这个期間的生理过程。低性繁外器官

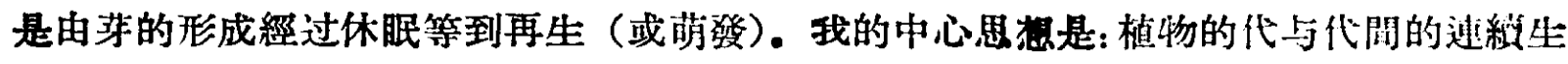
理过程。也是植物“傳代器官”（有性焎性）的形成、延存和再生的生理。也是植物在“傳 代” 过程中整体或局部器官生活力的提高、延存和恢复的生理. 在这里有性和然性繁殖 是看成基本上相似的过程. 这里也包含多年生植物（如頻果）的越冬芽的生理。它們的

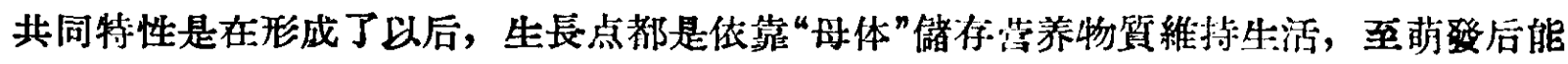
淮行光合作用为止。如果这个看法是可以的話, 此項研究包括下列內容:

（1）受精过程及胚發育的生理生化研究。在理論上, 动物胚胎学中早已有竍多工 作。植物学中只在 1950 年左右曹宗巽睢有較完全的研究。我建議我國植物生理学者应在 这个基礎上進一步結合实际問題研究：性別測定及性別的改变（如油桐、銀杏、瓜类的 花及果实的性別監定及改变)，雜㚆优势的原因，受精生理（不㝋性、空粒、“槍樶”， 作物的复强生理研究。在这里应指出苏联在性別生理上的高度成就和淮展。关于湖維卜 素对花粉的萌發及花粉管的生長的刺激作用, 是一个特殊的進展。

（2）休眠現像的生理过程。休眠期的延長及打破（薯类休眠, 葱蒜的休眠等, 如 
林傳光和張啺关于馬鈴著的工作)，谷类种子及椡木种子的休眠（趙同芳等的工作）。

（3）种子及果实的成熟及生理生化过程一一發展为储藏生理。見下段。

（4）荣樹花芽生理一一耛合大小年問題進行研究。兴城農業試驗場、華东農研所 已有工作。

限期具体任务: 立即將（3）項撗大，成为儲藏生理研究，設立尃門机棈。針对農 業生產計划中要求儲备兩年粮食的要求, 在三年內必需將种子（粮食）儲藏生理的一些 基本生理资料作出, 提供建筑粮倉的依据. 此項工作在植物生理所趙同芳領導下曾經有 很好基礎, 应擴大, 乎与复旦大学、昆虫所、植病室及粮食部合作。

\section{九 比較植物生理学（或“个別生理”）}

过去及目前向無此項研究。目的在比較各利类型（系統發有类型如高等低等、水生 陸生、菜本木本等) 植物的生活过程中各部分、各功能（个体發育）的表現, 特性及对 环境要求。建議的起因是: 農業上今后必須的基礎知墥, 和今后稙物生理的一个可能的 墢展, 即結合对个別具体植物的生理㕷性的研究。由这些精細知識去了解一般的規律。 这門研究的要求是: (1)作为栽培技術的生理基礎, 如同人体生理的精确知識在医学上 的作用。(2) 作出生理指标以为抗性、施肥、需水及生活情况的指标, 同診断指标。在 理論上是一个長期的規划, 去進行比較系統發育与个体發有中的生理功能及变异。

这个題目本身有其矛盾性: 范图太展, 同时植物不同人类, 它們的生理㕷性是有季 節性和地区性的。正因为此, 这个題目目前只限于几种主要農作物或必要的植物（如水 藻)。矛盾的关鍵在这个工作有高度的集体性組織性, 应分若千大区淮行。这正是目前 尤其是今后大規模机械化后, 農場企業化后必需的資料。希望在 12 年內能先在各大区作 出稻棉麥的“生理習性”作为指導栽培技術之用。

由科学院領導, 訂出具体一致的規格与要求, 由各大区農研所、涫等院校等分別在 各区結合当地条件進行研究和覌察。举例如下: 比較水、陸（和、粳）稻各生長期間各 器官的生長、呼吸、光合……等的性質和强度, 化学成分的变化, 器官的形成以及影响 这些过程的因子，同这些生理过程对环境的要求（如氧、砤質、水、光等), 及与其有关 的生理特征。这个工作初看起來似乎漫無边际, 实际上或早或晚各个農業研究机粠或國 营農場均須为了自己的地区淮行这类工作。不过如有个全國性的全盤部划, 那末方法、 对像、目标可以更集中, 凟料更可起理論及实䪙上的作用.

\section{+ 植物生物化学}

植物生物化学应当是一門与植物生理学本行的独立科学 (学科), 但是在中國和世界 目前情况下, 暫时作为植物生理的一个項目 (中心問題)。理由: 此門科学在世界上只有 少数國家这样分出 (如美國的个別机㩐), 同时我个人意見, 如果将其分出成为一門独立 学科, 則应併入生物化学范圍中去。它的研究中心应同普通生物化学一样, 包括蛋白質、 脂肪、碳水化物、酶、中間代謝等等, 而研究的对象是植物而已。在中國情况下, 目 前由于幹部缺乏, 如將其分出去, 不但它本身力量薄弱, 科会减弱植物生理学本身, 因此將其作为植物生理学的一个項目。以后再看条件, 可以分为一个独立学科。 
在三个五年計划內, 植物生物化学的范園, 从实际出發, 应該把它人为地局限于对 植物次級落品的研究, 粘合植物資源謂查及植物品的工業及農業利用, 光其是热带作 物与植物油。我認为这是实事求是的看法。

在目前应当立即开始的是植物次級复的分析和植物次級逢品的生物合成与地区环

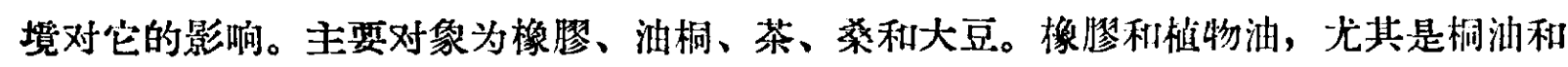
大豆，我國在世界上及在民主陆营中的独特性及其对工業的重姴性，使我們威到义不容 辞的㨁任去大力研究。

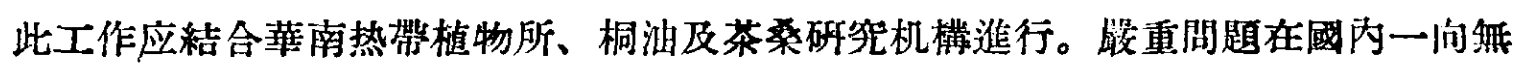
人在此問題上有經驗。只有在抗战期間在昆明做过一些初步工作，而当时培济洲的生化 工作者正走到一般代謝工作上面。有机分析工作迄末开始。目前植物生理所在没㝐和 罗士莘領灙下开始了一些工作。为了大力展开此項重要工作, 建淁: 1 . 将植物生理所生 化組的幹部作为中心在華南植物所开始工作及培养幹部。2.在 1956 年指派 $3-5$ 个有 机、生化和分析方面有一定基礎的幹部, 加 $1-2$ 个植物生理幹部到苏联科学院生化研 究所留学三年。3. 聘請苏联或民主德国植物生化専家來我國工作。4. 責成北京大学生物 系及化学系共同培养此項幹部。

\section{十一 植物生物物理}

同植物生物化学一样, 植物生物物理学应为一阴独立学科, 与植物生理学平行, 但 12 年計划內应作为植物生理学中一个項目。在世界范園內此項向是一門新的科学, 但有 極大的前途。特殊情况是國內有少数人对此項曾有些工作，而在电生理学上利有一些成 就。此門科学起源于 X光及鍢在医学上的应用, 以及 X光与紫外光对微生物的作用和对 湅胞遗傅的影响。近年加入高温低温、紅外光和超音波的生理作用。最近由于放射性同 位素应用的發展引起了更大的發展。以上的各項总括的包括在“輻射生理”項目中。子 顯微鏡学及 X光分析是此項目中的第二类內容, 研究細胞的“超顯微”結棈。此項中的第 三类內容是“电生理学”, 即应用动作电流测量植物的威应性。

“电生理学”方面已在威应性項目下談及。在國內細胞超㙷微結棈工作在植物中们未 开始, 只在亘絲形成的 $\mathrm{X}$ 光分析上留有过较有意义的工作。

在放射生理方面: 温度（热能）对枮物呼吸作用國人目作过工作，紫外光对微生物 的作用也有过工作。沈善昫等曾用紫外光照射放綫菌促淮抗生素的生産。李繶雄管在放 射性原子能对植物遺傳变异上工作过。这些工作应繼續, 利結合細胞遺傳学开展研究。 今后应注意到超音波对植物的作用。

放射性同位素的应用，应为今后發展的一項重要工作，用來作为研究光合、代謝、 硔留营养工作的工具。此項工作应派人去苏联学㕷，或請苏联専家 來指導，应于 1956 年开始。

\section{十二 今后的方向}

以上 11 个項目在分类上应是植物生理学的中心問題, 这些中心閔題应該在 1956 年 都开始有計划地动起來, 其中生殖生理与比較生理以往沒有过工作, 是 待 1956 年發展 
的。至于植物生理学的發展方向, 不論是國內或國外, 应当是这四方面: 1. 植物的物筫代 爵 ——就是有机物的同化与昗化, 包括光合、有机物代謝、礦物及水分代謝、植物生物 化学、細胞生理的一部分、生殖生理的一部分。2. 形态的变异一一包括生長与發直、細 胞生理、生殖生理的一部分。3. 能量的变异一一包括得很廣, 主要为植物生物物理、威 应性、細胞生理的一部分、光合作用的光的部分等。4. 植物比校 (个別) 生理与环境关 系 (包括適应性，对不良环境的抗性生理基礎）。

植物生理学研究机構的發展和設置的規划, 主要是結合本門学科的完整性和國家經 济計划的需要, 也就是应結合農業研究的要求。

机構方面, 我認为可以分为三类, 第一类是原則性、理論性和关践性問題的研究, 以現在的植物生理所（全面性的）为中心，数年內结后在全國各大自然区域設立分所。

第二类是農業科学院的植物生理研究所，应該在全國各大自然区域設立分所。研究 对僌可結合当地的主要農作物和經济作物, 以及当地特殊气候条件的影响。

第三类，在 1962 年开始重点試办國营農場植物生理工作站。

幹部是决定工作开展及机構建立等一切事業的关旔, 人数的需要应該从这几点出發:

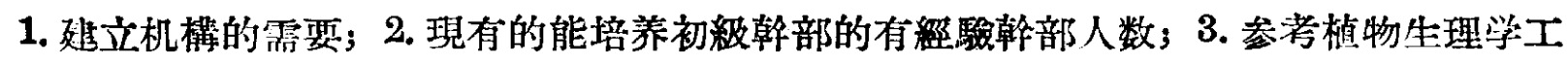
作有成績的咸家的工作人数。

以每个滈級幹部平均每7i年能帶出 5 个翰部（指相当于副研究員的水本）而綸，那末 根据我國現有的植物生工思学高級幹部來算, 到 1967 年, 可以培养出足矽数量的高級植 物生现学:暗部。

但是, 必須考虑到“原始幹部”的來源間題。目前只有北京大学有较完备的植物生理 專業, 全國生物系植物組的人数也不太多。因此必須再建立兩个植物生理尃業, 四、五 年后全國各綜合性大学都应該建立植物生理專業。

根据以上情况可以認为: 1. 目前大力开始培养幹部, 叫、五年后就可以䩗足机構要

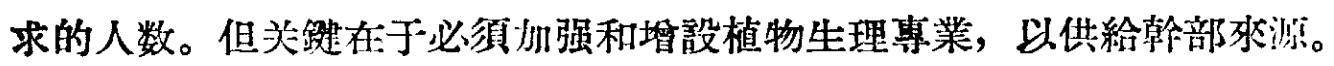

2. 在最近的四、五年內有幹部不足現像, 这是目前的关鍵。因此必须怕目前“牛成熟” 的幹部提前加速培前, 雨年內完成。

3. 美國 1955 年植物生理学会会員为美國人 981 名, 外國人 150 名。但 981 人中有的 是研究生, 有的非植物生理学工作人員; 也有未参加学会的植物生理学工作者。我們在 最近几年中虽然人数仍昍較少，但是可由加强工作的組械性和工作的計划性爽克服。

4. 最近的十年內中國植物生理幹部的人数是“被动的”——限于现有的“老科学“家”人 数和最低研究机構数字出發。十年后我們人数可轉入主动, 那时会有足晼的翰部, 可以 从合理的要求而决定机棈的多少和大小, 抹且來确定培养的人数。

以上的估計是保守的, 手且未把“外援”列入。可能請苏联尃家來培养或造人计國留 学。在培养翰部中一定要考慮吸收物理系、化学系、農学和工程系畢業的榦部。

再度颜明的，以上只是个人主覌的看法、想法同估计，作为進一步討論的开始。 